\title{
Potential of Fungal Endophytes to Antagonise Puccinia striiformis Causing Wheat Yellow Rust
}

Hafiz Arslan Anwaar ${ }^{1}$, Rashida Perveen ${ }^{1}$, Muhammad Zeeshan Mansha ${ }^{2}$, Hafiz Muhammad Aatif $^{2}$, Zahid Mahmood Sarwar ${ }^{3}$, Ummad ud din Umar ${ }^{1}$, Ch. M. Shahid Hanif ${ }^{2}$, Muhammad Sajid $^{1}$, Ateeq-ur-Rehman ${ }^{1}$, Muhammad Mohsin Alam ${ }^{1 *}$, Muhammad Subhan Shafique ${ }^{4}$

\author{
${ }^{I}$ Department of Plant Pathology, Bahauddin Zakariya University, Multan, Pakistan \\ ${ }^{2}$ College of Agriculture, Bahauddin Zakariya University, Bahadur Sub Campus, Layyah, Pakistan \\ ${ }^{3}$ Department of Entomology, Bahauddin Zakariya University, Multan, Pakistan \\ ${ }^{4}$ Department of Plant Pathology, University of Agriculture, Faisalabad, Pakistan \\ *Corresponding Author: \\ E-mail:mohsinalam@bzu.edu.pk phone:+92-300-8206128 \\ E-mail: arslan1757@gmail.com phone: +92-333-4005950
}

\begin{abstract}
In this study, we evaluated the potential of fungal endophytes to control yellow rust in wheat (Triticum aestivum L.) as endophytes are beneficial microbes and alternate to pesticides for confronting pathogens. The in-vitro efficacy of the fungal endophytes isolated from different desert plants was evaluated and the best four namely Colletotrichum lindemuthianum, Piriformospora indica, Acremonium lolii and Trichoderma viride were selected. Seeds of two susceptible wheat genotypes namely Fareed-06 and Shafaq-06 obtained from screening experiment were inoculated by dipping in four endophytic spore suspensions and were sown using randomized complete block design under factorial arrangement. Data concerning about area under disease progress curve, final disease severity percentage, coefficient of infection,1000- grains weight and grain yield were recorded. Results showed that endophyte $P$. indica showed significant decrease in final disease severity (FDS) and area under disease progress curve (AUDPC), resultantly $12.2 \%$ grain yield gain in rust susceptible wheat genotypes of Fareed-06 and Shafaq-06 followed by the endophytes $T$. viride, $C$. lindemuthianum and A. lolii with the grain yield gain of $10.6 \%, 06.2 \%$ and $04.2 \%$ respectively. In crux, fungal endophytes are valuable microbes which can be employed to induce tolerance against $P$. striiformis in yellow rust vulnerable areas for better and sustainable wheat production.
\end{abstract}

Keywords: Piriformospora indica; Trichoderma viride; final disease severity; grain yield and tolerance 


\section{INTRODUCTION}

Wheat (Triticum aestivum L.) is widely cultivated cereal crop in the majority of the world regions and is the vital and essential staple food of $36 \%$ world's population ( 2 billion people) [1]. The food security is highly focused on obtaining more food to fulfil the needs of burgeoning population which can only be accomplished when the production of wheat as well as other cereal crops is increased globally. The wheat crop is often low as contrast to its actual capacity in terms of production and yield because it hit by many of the abiotic and biotic maladies [2]. Among biotic factors, diseases badly affect wheat yield in which rusts have caused huge yield losses and significant damage in recent years. Wheat rusts are prevalent throughout the world and its new races are evolving unremittingly day by day and infecting resistant varieties [3].

Yellow rust of wheat caused by basidiomycete fungus Puccinia striiformis is the most significant wheat disease worldwide favoured cool summer, mild winter, long cool and wet spring. Owing to its economic and social losses, it is presently unsympathetic threat to the global food security [4]. Susceptible genotypes show the appearance of yellow streaks on the leaves, followed by elongated, bright yellow, small pustules arranged in obvious rows on leaf sheaths, awns and glumes resultantly spores accumulation within the florets and on developing grain. Seed produced from rust damaged crop express low vigour and poor emergence after germination. Wheat yield losses of $10-70 \%$ depend on initial infections, susceptibility of the genotypes, inoculum density and its multiplication rate [5]. Early infection causes $100 \%$ yield loss on susceptible genotypes whereas disease persists to develop during the whole growing season [6].

To minimize the severe wheat yield losses by different pathogenic diseases and abiotic stresses, appropriate strategies might be adopted. Numerous scientists and researchers are discovering sustainable alternative approaches to pesticides and chemical fertilizers. 
Natural resources are decreasing with the passage of time due to spontaneously increasing world population. Hence, it is dire need of the hour to find out an alternative and viable approach for growing more food in such a manner that can reduce detrimental environmental impacts of intensive farming, fungicide resistance and environmental pollution. Among these approaches, biological control of pathogens by using endophytes is a cost effective and environment safe approach to minimize the use of pesticides in cereals.

Endophytes are metabolically active fungal or bacterial microbes with internal colonization, inconspicuous infections, transiently symptomless and diverse life history strategies [7-8]. The beneficial impact of endophytes to plant diseases have amplified the concern of farmers and researchers for augmenting agricultural production. Endophytes antagonise disease pathogens directly by hyperparasitism, production of lytic enzymes and antimicrobial metabolites, indirectly by inducing systemic resistance, contending for space and nutrients and endorsing plant growth [9-10]. In our previous research, numerous fungi that colonized different desert plants endophytically have been screened to evaluate their potential to promote wheat growth and to combat leaf rust pathogens. Four of the selected fungal endophytes displayed great potential in controlling Puccinia recondita causing wheat leaf rust in field conditions [11]. In present study, we screened several fungal endophytes and investigated the inhibitory capacities of the four selected isolates against Puccinia striiformis to wheat susceptible genotypes in artificially inoculated diseased conditions.

\section{MATERIALS AND METHODS}

\section{Experimental Site and Sowing Conditions}

Fifty local genotypes of wheat were sown for screening to yellow rust in the reseachh field area of Bahauddin Zakariya University, Multan during December, 2015. Each genotype was planted in experimental plot size of $1.2 \mathrm{~m}$ x $2.5 \mathrm{~m}$ surrounded by three rows of highly susceptible genotype Morocco. Rust inoculation methods like needle injection, rubbing, 
spraying and dusting with talcum powder were exploited at tillering and heading stage on Morocco for the development of a heavy pressure of rust infection [11-12]

\section{Data Recording of Yellow Rust}

Rust severity in percentage and host response was recorded by modified Cobb's scale described by Peterson [13]. Rust severity was recorded four times with the consecutive gap period of 10 days while Morocco expressed 40-50\% severity. Rating of the final disease severity (FDS) was noted as Morocco showed 90-100\% severity. Coefficient of infection (CI) values were calculated for the rating of host responses of susceptible (S), resistant (R), moderately susceptible (MS) and moderately resistant (MR) [14]. For each genotype, area under disease progress curve (AUDPC) with 10 days interval was calculated by the following equation [15].

$$
\begin{aligned}
& \text { AUDPC }=\mathbf{d}\left[\mathbf{1} / \mathbf{2}\left(\mathbf{y}_{1}+\mathbf{y}_{\mathbf{k}}\right)+\left(\mathbf{y}_{2}+\mathbf{y}_{3}+---+\mathbf{y}_{\mathbf{k}-1}\right)\right] \\
& \text { Where, } \mathrm{d}=\text { days between two consecutive records (time intervals) } \\
& \quad \mathrm{y}_{1}+\mathrm{y}_{\mathrm{k}}=\text { Sum of the } 1 \mathrm{st} \text { and last disease scores } \\
& \mathrm{y}_{2}+\mathrm{y}_{3}+----+\mathrm{y}_{\mathrm{k}-1}=\text { Sum of all in between disease scores. }
\end{aligned}
$$

\section{Isolation of Fungal Endophytes}

Samples of naturally occurring healthy roots, leaves and stems were taken at random from the various desert locations of Thar, Cholistan and Rohi and were shifted to the mycology and genetics lab through ice bucket for isolation of endophytes. Samples were sterilized, incubated for the emergence of endophytic fungi, purified and identified by the techniques described previously [11].

\section{Optimization of efficient and compatible endophytic fungi with wheat seed}

Spores of many endophytic fungi were harvested in distilled water by rubbing the surface of a sporulating pure culture with a sterile bent glass rod and maintained the spore suspension of $1 \times 10^{6} \mathrm{ml} / \mathrm{L}$ by dilution method. Germinating wheat seed were kept in test tubes containing $0.3 \%$ agar concentration in distilled water with fungal spore suspension of $1 \times 10^{6} \mathrm{ml} / \mathrm{L}$ and were incubated. After suitable intervals, root and shoot length of wheat 
seedlings were measured for investigating the efficacy of fungal endophytes. Consequently four best endophytes were selected for further experimentation.

\section{In-Vivo Potential of Fungal Endophytes}

Seeds of two certain yellow rust susceptible genotypes of wheat were soaked separately for $24 \mathrm{~h}$ in spore suspensions of four nominated (from lab experiments) efficient and compatible endophytes. During last week of November, 2015, these seeds were sown under randomized complete block design through factorial arrangement repeated thrice and untreated as control. Inoculation was done artificially as performed in screening experiment. The FDS (\%), AUDPC value, 1000-grain weight $(\mathrm{g})$, Grain yield $\left(\mathrm{gm}^{-2}\right)$ and yield increased (\%) were measured for assessing the potential of fungal endophytes against yellow rust fungus $P$. striiformis as well as their symbiotic response for rust susceptible genotypes in disease vulnerable conditions. The endophytes were re-isolated and identified from the inoculated host plants to confirm the colonization of the fungal endophytes within tissues.

\section{Statistical analysis}

Data were analysed using analysis of variance (ANOVA) and Dunkun's New Multiple Range Test (DNMRT), Tukey's test at 5\% probability level in screening experiment and Least Significant Difference (LSD) test for other experiment [16]

\section{RESULTS}

\section{Yellow Rust Susceptibility of Wheat Genotypes}

The yellow rust significantly affected the local wheat genotypes presenting final disease severity ranged from 20-80\% (Table 1). The genotypes of Shafaq-06, Fareed-06, MH-97 and Chenab-00 exhibited the highest of $80 \%$ final disease severity followed by Inqalab-91 and Aas-02 (Table 1). Correspondingly, the highest values of AUDPC and CI were recorded in genotypes of Fareed-06 (1463, 76.0), MH-97 (1413, 76.0), Shafaq-06 (1400, 76.0), Inqalab-91 $(1367,76.0)$, Chenab-00 $(1283,76.0)$ and Aas-02 $(1283,78.0)$, respectively 
and were entitled as susceptible, whereas both Faisalabad-08 and Bhakhar-08 depicted the CI values of 8.0, and also the lowest AUDPC values of 200 and 265, thus, were highly resistant to the yellow rust pathogen (Puccinia striiformis). The rest of the genotypes were ranked as moderately resistant to susceptible depicting the range of values 300 to 465 for portraying their resistance as well as 475 to 850 susceptibility (Table 1).

\section{Changes in Disease Tolerance with Fungal Endophytes}

From diverse endophytes, the four endophytes namely Acremonium lolii, Colletotrichum lindemuthianum, Piriformospora indica, and Trichoderma viride were designated as efficient and compatible for potentially aggressive against Puccinia striiformis, derivative of in-vitro evaluation. Endophytic impact was appraised on yellow rust susceptible genotypes Shafaq-06 and Fareed-06 in disease conditions pacing artificially. These susceptible genotypes revealed significant outcomes posing with fungal endophytes.

Endophytic inoculation as seed priming improved thousand grains weight and grain yield by falling the FDS and AUDPC values of yellow rust susceptible genotypes in rust vulnerable conditions comparative to control. Fungal endophytes abridged disease severity effectually as $40 \%$ FDS was witnessed in Piriformospora indica followed by Trichoderma viride (50\%), Colletotrichum lindemuthianum (55\%) and Acremonium lolii (60\%), respectively (Table 2). Amid the examined genotypes, Fareed-06 indicated slightest FDS (56\%) than that of Shafaq-06 (58\%). Likewise, least AUDPC value (625.0) was observed in P. indica followed by Trichoderma viride (800.0), Colletotrichum lindemuthianum (933.3) and Acremonium lolii (1104.2), comparative to control condition (no endophytic inoculation) to the susceptible wheat genotypes (Table 2).

Symbiotic impact of fungal endophytes to susceptible wheat genotypes and potentially aggressive input for Puccinia striiformis were contributed significantly for alleviating wheat 
plant to yellow rust through antagonising the disease attack by subsiding disease severity consequently enhanced thousand grain weight and grain yield (Table 2). $P$. indica indicated significant performance by increasing $12.3 \%$ grain yield comparing to control followed by $T$. viride $10.6 \%$, C. lindemuthianum $6.2 \%$ and A. lolii $4.2 \%$ in yellow rust conditions. Both grains weight and yield were effectually improved by the symbiosis of $T$. viride and $P$. indica while the $C$. lindemuthianum and $A$. lolii revealed moderate performances for conferring tolerance against Puccinia striiformis.

\section{DISCUSSION}

Although a number of the reports endorse the improvement in wheat growth by the exogenous employment of $P$. indica and substantiated that its association with host augmented the defence mechanisms, conferred disease tolerance and amplified wheat productivity and yield [17-18] but none is available in prior findings where $P$. indica and other fungal endophytes antagonised wheat yellow rust in field. In present study, fungal endophytes were utilized for the improvement of the wheat growth and yield in yellow rust disease conditions. Exploitation of fungal endophytes ascertained extremely efficacious in enriching the yield of susceptible genotypes (Fareed-06 and Shafaq-06). P. indica exhibited paramount valuable outcomes followed by $T$. viride, C. lindemuthianum and A. lolii for prompting tolerance against $P$. striiformis. Findings of current study validated better grains weight and yield interconnected principally to the decreased disease severity of the endophytic associated wheat host. Enlarged photosynthetic area and net assimilation efficiency of host inferred the potentially antagonistic and aggressive role of fungal endophytes. Decreased disease severity details of larger surface area for producing and partitioning of photoassimilates towards reproductive growth, thus, better grains weight and yield. 
The potential of fungal endophytes against yellow rust fungus $P$. striiformis contributed substantially for stabilizing susceptible wheat host in disease conditions by stimulating disease tolerance. Alike, Rodriguez and Suryanarayanan [19-20] informed antagonistic role of $C$. lindemuthianum in Solanum lycopersicum with augmented disease resistance and improved growth and biomass as witness in current study. Numerous studies conveyed the antagonistic role of $T$. viride as well as other Trichoderma spp. for prompting positive impact to the hosts and copping with diverse diseases [21-23].

In our previous studies [11], the four fungal endophytes $P$. indica, T. viride, $C$. lindemuthianum and A. lolii showed paramount valuable outcomes for prompting tolerance against fungus $P$. recondita in leaf rust susceptible wheat genotypes by decreasing final disease severity (FDS) 30-60\% and area under disease progress curve (AUDPC), resultantly achieved the $12.2 \% 10.6 \%, 06.2 \%$ and $04.2 \%$ grain yield gain, respectively.

Consistent with Rabiey and Shaw [24] P. indica exploitation in wheat decreased 70\% disease severity of Fusarium head blight, improved thousand grains weight and grain yield. The average rise of 24.2 and $17.3 \%$ for thousand grains weight and grain yield were observed. In another study, $P$. indica employment at sowing time decreased the disease severities of septoria leaf blotch, powdery mildew and yellow rust by 65, 63, and 29\%, respectively. Subsequently, it also improved wheat grain yield by 27,48 and $25 \%$, respectively [25]. Thus, deeming the substitute of chemical fungicide, fungal endophytes utilization is expedient in getting better and sustainable wheat yield from yellow rust vulnerable areas.

\section{CONCLUSIONS}

Fungal endophytes can protect Triticum aestivum (bread wheat) from destruction caused by fungus $P$. striiformis through declining the disease severity and subsequently improve the grain yield in field conditions. The outcomes of current study implied that 
symbiotic association of $T$. viride, $P$. indica, A. lolii and $C$. lindemuthianum with wheat host could induce tolerance against yellow rust.

\section{CONFLICT OF INTEREST}

The authors of the article certify that they have NO affiliations with or involvement in any organization or entity with any financial interest or non-financial interest in the subject matter or materials discussed in this manuscript.

\section{AUTHOR CONTRIBUTION}

Formal analysis, Hafiz Aatif; Investigation, Zahid Sarwar; Methodology, Muhammad Sajid; Project administration, Ateeq Rehman; Software, Muhammad Mansha; Supervision, Rashida Perveen; Visualization, Ummad ud din Umar, Ch. Hanif and Muhammad Shafique; Writing original draft, Hafiz Anwaar; Writing - review \& editing, Muhammad Alam.

\section{REFERENCES:}

[1] United States Department of Agriculture (USDA), World Agriculture Production, March 2017

[2] Jellis, G. J. Combating the Pressures on Production Systems in a Changing World. Crop Plant Resistance to Biotic and Abiotic Factors: Current Potential and Future Demands, Proceedings of the 3rd International Symposium on Plant Protection and Plant Health in Europe held at the Julus Kühn-Institut, Berlin-Dahlem, Germany, 14-16 May 2009 $1-1$.

[3] Waqar, A.; Khattak, S.H.; Begum, S.; Rehman, T.; Rabia,; Shehzad, A.; Ajmal, W.; Zia, S. S.; Siddiqi, I.; Ali, G.M. Stripe rust: A review of the disease, Yr genes and its molecular markers. Sarhad J. Agric. 2018, 34, 188-201.

[4] Hovmøller, M. S.; Sørensen, C. K.; Walter, S.; Justesen, A. F. Diversity of Puccinia striiformis on cereals and grasses. Annu. Rev. Phytopathol. 2011, 49, 197-217.

[5] Chen, X. M. Epidemiology and control of stripe rust (Puccinia striiformis f. sp. tritici) on wheat. Can J Plant Pathol. 2005, 27, 314-337.

[6] Chen, X. M. High-temperature adult-plant resistance, key for sustainable control of stripe rust. Am. J. Plant Sci. 2013, 4, 608-627.

[7] Hardoim, P. R.; Van Overbeek, L. S.; Berg, G.; Pirttilä, A. M.; Compant, S.; Campisano, A.; Matthias, D.; Sessitsch, A. The hidden world within plants: ecological and evolutionary considerations for defining functioning of microbial endophytes. Microbiol Mol Biol Rev. 2015, 79, 293-320. 
[8] Irabor, A.; Mmbaga, M. T. Evaluation of selected bacterial endophytes for biocontrol potential against Phytophthora Blight of bell pepper (Capsicum annuum L.). J Plant Pathol Microbiol. 2017, 8, 424.

[9] Kavamura, V. N.; Santos, S. N.; da Silva, J. L.; Parma, M. M.; Ávila, L. A.; Visconti, A.; Zucchi, T.D.; Taketani, R.G.; Andreote, F.D.; de Melo, I. S. Screening of Brazilian cacti rhizobacteria for plant growth promotion under drought. Microbiol. Res. 2013, 168, 183-191.

[10] Mmbaga, M. T.; Mackasmiel, L. M.; Mrema, F, A. Evaluation of biological control agents for macrophomina root rot and powdery mildew in flowering dogwood (Cornus florida L.). Hort Sci. 2018, 52: In press.

[11] Anwaar, H.A.; Ali, S.; Sahi, S.T.; Siddiqui, M.T. Evaluating the antagonistic role of fungal endophytes against leaf rust of wheat caused by Puccinia recondita. Intl. J. Agric. Biol. 2018, 21, 333-337.

[12] Hussain, M.; Khan, M. A.; Hussain, M.; Javed, N.; Khaliq, I. Application of phenotypic and molecular markers to combine genes for durable resistance against rust virulences and high yield potential in wheat. Intl. J. Agric. Biol. 2015, 17, 421-430.

[13] Peterson, R. F.; Campbell, A. B.; Hannah, A. E. A diagrammatic scale for estimating rust intensity on leaves and stems of cereals. Can. J. Res. 1948, 26, 496-500.

[14] Pathan, A. K.; Park, R. F. Evaluation of seedling and adult plant resistance to leaf rust in European wheat cultivars. Euphytica. 2006, 149, 327-342.

[15] Pandey, H. N.; Menon, T. C. M.; Rao, M. V. A simple formula for calculating area under disease progress curve. Barley and Wheat Newsletter, 1989.

[16] Steel, R. Analysis of variance I: The one-way classification. Principles and Procedures of Statistics A Biometrical Approach, 1997, 139-203.

[17] Shahabivand, S.; Maivan, H. Z.; Goltapeh, E. M.; Sharifi, M.; Aliloo, A. A. The effects of root endophyte and arbuscular mycorrhizal fungi on growth and cadmium accumulation in wheat under cadmium toxicity. Plant Physiol Biochem. 2012, 60, 53 58.

[18] Yaghoubian, Y.; Goltapeh, E. M.; Pirdashti, H.; Esfandiari, E.; Feiziasl, V.; Dolatabadi, H. K.; Verma, A.; Hassim, M. H. Effect of Glomus mosseae and Piriformospora indica on growth and antioxidant defense responses of wheat plants under drought stress. Agr Res. 2014, 3, 239-245.

[19] Rodriguez, R. J.; White Jr, J. F.; Arnold, A. E.; Redman, A. R. A. Fungal endophytes: diversity and functional roles. New Phytol, 2009, 182, 314-330.

[20] Suryanarayanan, T. S.; Thirunavukkarasu, N.; Govindarajulu, M. B.; Sasse, F.; Jansen, R.; Murali, T. S. Fungal endophytes and bioprospecting. Fungal Biol. Rev. 2009, 23, 9-19

[21] Mastouri, F.; Björkman, T.; Harman, G. E. Seed treatment with Trichoderma harzianum alleviates biotic, abiotic, and physiological stresses in germinating seeds and seedlings. Phytopathology. 2010, 100, 1213-1221.

[22] Montero-Barrientos, M.; Hermosa, R.; Cardoza, R. E.; Gutierrez, S.; Nicolas, C.; Monte, E. Transgenic expression of the Trichoderma harzianum hsp70 gene increases 
Arabidopsis resistance to heat and other abiotic stresses. J. Plant Physiol. 2010, 167, 659-665.

[23] Shoresh, M.; Harman, G. E.; Mastouri, F. Induced systemic resistance and plant responses to fungal biocontrol agents. Annu. Rev. Phytopathol. 2010, 48, 21-43.

[24] Rabiey M,; Shaw, M. W. Piriformospora indica reduces Fusarium head blight disease severity and mycotoxin DON contamination in wheat under UK weather conditions. Plant Pathol. 2016, 65, 940-952 Doi: 10.1111/ppa.12483.

[25] Rabiey, M.; Ullah, I.; and Shaw, M. W. The endophytic fungus Piriformospora indica protects wheat from fusarium crown rot disease in simulated UK autumn conditions. Plant Pathol. 2015, 64, 1029-1040.

Table 1: Impact of wheat yellow rust on final disease severity, area under disease progress curve and coefficient of infection in field conditions

\begin{tabular}{|c|c|c|c|c|}
\hline Genotypes & FDS & AUDPC & CI & IR \\
\hline Aas-02 & 80 & 1283 & 78 & $\mathrm{~S}$ \\
\hline Chenab-00 & 80 & 1283 & 76 & $\mathrm{~S}$ \\
\hline Fareed-06 & 80 & 1463 & 76 & $\mathrm{~S}$ \\
\hline Inqalab-91 & 80 & 1367 & 76 & $\mathrm{~S}$ \\
\hline MH-97 & 80 & 1413 & 76 & $\mathrm{~S}$ \\
\hline Shafaq-06 & 80 & 1400 & 76 & $\mathrm{~S}$ \\
\hline Kohistan-97 & 70 & 875 & 64 & $\mathrm{~S}$ \\
\hline $\mathrm{Pb}-11$ & 70 & 1042 & 63 & $\mathrm{~S}$ \\
\hline SH-02 & 70 & 875 & 64 & $\mathrm{~S}$ \\
\hline Shaheen-94 & 70 & 983 & 64 & $\mathrm{~S}$ \\
\hline Watan-92 & 70 & 945 & 58 & $\mathrm{~S}$ \\
\hline Fsd-83 & 60 & 825 & 51 & $\mathrm{~S}$ \\
\hline Hashim-10 & 60 & 925 & 51 & $\mathrm{~S}$ \\
\hline Moomal-02 & 60 & 825 & 50 & $\mathrm{~S}$ \\
\hline Parsab-08 & 60 & 825 & 50 & $\mathrm{~S}$ \\
\hline 9610 & 50 & 800 & 37 & $\mathrm{MS}$ \\
\hline Kohenoor-83 & 50 & 900 & 40 & $\mathrm{MS}$ \\
\hline LU-26 & 50 & 765 & 37 & MS \\
\hline Millat-11 & 50 & 775 & 38 & $\mathrm{MS}$ \\
\hline $\mathrm{Pb}-85$ & 50 & 675 & 38 & $\mathrm{MS}$ \\
\hline Pict-62 & 50 & 615 & 37 & MS \\
\hline 9495 & 40 & 465 & 27 & MR \\
\hline 9725 & 40 & 725 & 25 & $\mathrm{MR}$ \\
\hline AARI-11 & 40 & 515 & 28 & MR \\
\hline Anmol-91 & 40 & 725 & 25 & MR \\
\hline Chakwal-50 & 40 & 625 & 25 & MR \\
\hline GA-02 & 40 & 502 & 25 & $\mathrm{MR}$ \\
\hline Glaxy-13 & 40 & 465 & 25 & MR \\
\hline Gomal-08 & 40 & 450 & 25 & MR \\
\hline Kohsar-95 & 40 & 542 & 25 & MR \\
\hline NARC-08 & 40 & 515 & 28 & MR \\
\hline
\end{tabular}




\begin{tabular}{|l|c|c|c|c|}
\hline Pak 81 & 40 & 500 & 24 & MR \\
\hline Parwaz-94 & 40 & 525 & 28 & MR \\
\hline Pbw-222 & 40 & 725 & 24 & MR \\
\hline Pirsabak-04 & 40 & 750 & 24 & MR \\
\hline Potohar-73 & 40 & 725 & 25 & MR \\
\hline 9444 & 30 & 465 & 15 & $\mathrm{R}$ \\
\hline Abadghar-93 & 30 & 300 & 15 & $\mathrm{R}$ \\
\hline Aas-11 & 30 & 475 & 19 & $\mathrm{R}$ \\
\hline Bathoor-08 & 30 & 450 & 15 & $\mathrm{R}$ \\
\hline Fsd-85 & 30 & 450 & 19 & $\mathrm{R}$ \\
\hline Iqbal-00 & 30 & 400 & 19 & $\mathrm{R}$ \\
\hline Lasani-06 & 30 & 450 & 19 & $\mathrm{R}$ \\
\hline Manthar-03 & 30 & 450 & 19 & $\mathrm{R}$ \\
\hline Saher-06 & 30 & 400 & 19 & $\mathrm{R}$ \\
\hline SH-95 & 30 & 475 & 15 & $\mathrm{R}$ \\
\hline Uqab-00 & 30 & 300 & 19 & $\mathrm{R}$ \\
\hline Wafaq-01 & 30 & 300 & 19 & $\mathrm{R}$ \\
\hline Bhakhar-02 & 20 & 265 & 8 & $\mathrm{R}$ \\
\hline Fsd-08 & 20 & 200 & 8.0 & $\mathrm{R}$ \\
\hline
\end{tabular}

FDS $=$ Final disease severity, AUDPS $=$ Area under disease progress curve, $\mathrm{CI}=$ Coefficient of infection, IR= Infection response

Table 2: Potential of fungal endophytes confronting fungus of wheat yellow rust $P$. striiformis in field conditions

\begin{tabular}{|c|c|c|c|c|c|}
\hline Factors & FDS & $\overline{\text { AUDPC }}$ & TGW & GY & YI \\
\hline \multicolumn{6}{|l|}{ Genotypes (G) } \\
\hline Fareed-06 & $56.0 \mathrm{~A}$ & $961.6 \mathrm{~A}$ & $36.2 \mathrm{~B}$ & $256.8 \mathrm{~B}$ & $7.17 \mathrm{~B}$ \\
\hline Shafaq-06 & $58.0 \mathrm{~A}$ & $953.3 \mathrm{~A}$ & $38.1 \mathrm{~A}$ & $276.2 \mathrm{~A}$ & $9.41 \mathrm{~A}$ \\
\hline \multicolumn{6}{|l|}{ Endophytes (E) } \\
\hline Control & $80.0 \mathrm{~A}$ & $1325.0 \mathrm{~A}$ & $34.5 \mathrm{E}$ & $248.1 \mathrm{C}$ & $0.00 \mathrm{E}$ \\
\hline C.lindemuthianum & $55.0 \mathrm{BC}$ & $933.3 \mathrm{BC}$ & $36.6 \mathrm{C}$ & $264.5 B$ & $6.15 \mathrm{C}$ \\
\hline A. lolii & $60.0 \mathrm{~B}$ & $1104.2 B$ & $35.9 \mathrm{D}$ & $259.0 \mathrm{~B}$ & $4.18 \mathrm{D}$ \\
\hline T. viride & $50.0 \mathrm{BC}$ & $800.0 \mathrm{C}$ & $38.8 \mathrm{~B}$ & $278.0 \mathrm{~A}$ & 10.61B \\
\hline$P$. indica & $40.0 \mathrm{C}$ & $625.0 \mathrm{D}$ & $40.0 \mathrm{~A}$ & $283.0 \mathrm{~A}$ & $12.25 \mathrm{~A}$ \\
\hline \multicolumn{6}{|l|}{$\operatorname{LSD}(p \leq 0.05)$} \\
\hline $\mathrm{G}$ & 11.9 & 109.9 & 0.3367 & 3.5703 & 0.7570 \\
\hline $\mathrm{E}$ & 18.9 & 173.9 & 0.5324 & 5.6451 & 1.1970 \\
\hline $\mathrm{G} \times \mathrm{E}$ & 26.7 & 245.9 & 0.7529 & 7.9834 & 1.6928 \\
\hline \multicolumn{6}{|l|}{ F-value } \\
\hline G & $30.00^{\mathrm{NS}}$ & $521^{\mathrm{NS}}$ & $28.6163 * *$ & $2842.13 * *$ & $23.941 * *$ \\
\hline $\mathrm{E}$ & $1320.00^{* *}$ & $438771 * *$ & $29.5270 * *$ & $1201.28 * *$ & $146.476^{* *}$ \\
\hline $\mathrm{G} \times \mathrm{E}$ & $30.00^{\mathrm{NS}}$ & $10625^{\mathrm{NS}}$ & $0.5963 *$ & $56.72^{\mathrm{NS}}$ & $4.550 * *$ \\
\hline
\end{tabular}

FDS $=$ Final disease severity, AUDPS $=$ Area under disease progress curve, TGW $=$ Thousand grains weight, $\mathrm{GY}=$ Grain yield, $\mathrm{YI}=$ Yield increased 
